\title{
Commodity Prices and the U.S. Price Level
}

\begin{abstract}
AN IMPORTANT ASPECT of the recent high rates of inflation in both the United States and other countries has been the sharp increases in prices of raw commodities. To be sure, prices of primary industrial products usually have risen significantly during cyclical upswings, particularly during the phase when output is accelerating. Prices of raw agricultural commodities are also responsive to demand to some degree, although their most striking movements are usually induced by changes in supply. That the recent advance in raw commodity prices was one of the largest experienced in the United States is generally attributed to two factors: (1) the coincidence of the general business expansion in the United States with a reduction in the supply of some major agricultural products; and (2) the coincidence of the acceleration in general business expansions in the United States and other countries.

The purpose of this paper is to explore the impact of this worldwide surge in the prices of raw commodities on the price level in the United States in $1973 .^{1}$ The analysis uses an econometric model of price behavior by stage of process.
\end{abstract}

Note: Lydia Segal and Rosemary Quintano assisted in the research for this paper. The author is solely responsible for the views expressed and any errors of analysis.

1. Such an analysis assumes that the rise in raw commodity prices, in the short run at least, affects the overall price level and not merely relative prices. Specifically, it assumes that overall prices are not completely determined by the supply of money in the short run. 


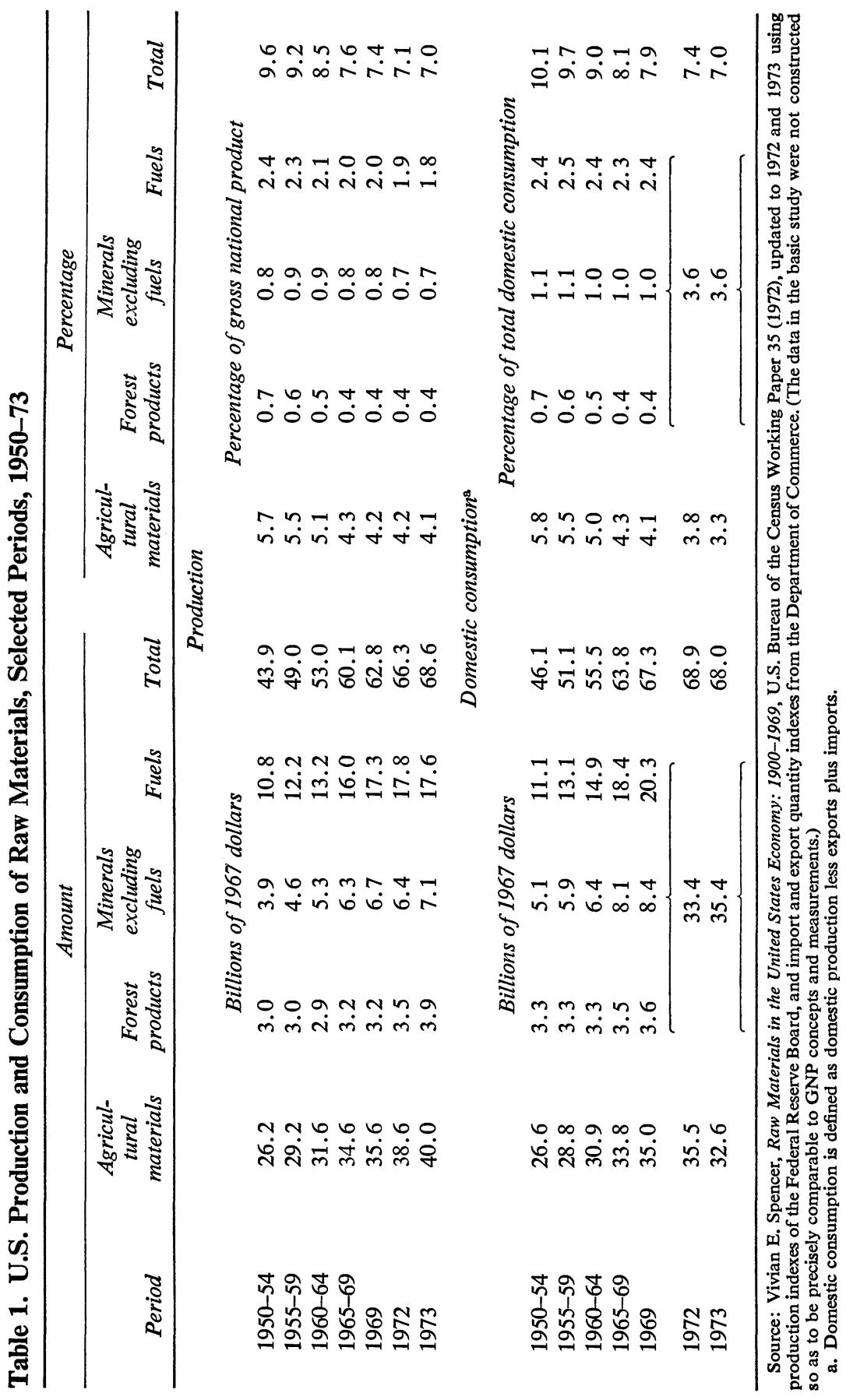




\section{Raw Commodities in the U.S. Economy}

Raw materials make up a relatively small and declining share of the nation's output. Domestic output of raw commodities accounted for about 7 percent of gross national product, in 1967 dollars, in 1973 (see Table 1). This share had declined from about 10 percent twenty years earlier, with about half of the overall drop in agricultural materials, and the remainder in fuels and forest products. Raw commodities also accounted for about 7 percent of total consumption in the United States in 1973 (defined as domestic production less exports), showing a similar drop from 10 percent in the early 1950s. Through 1972 the decline in the consumption share of raw commodities was about the same as that in the production share. In 1973, however, the consumption share dropped more sharply than the production share, reflecting increased agricultural exports.

One way to quantify the impact of commodity inflation on the GNP deflator is to subtract from the rise in the deflator the rise in commodity prices weighted by their importance in output. Prices of these commodities are estimated to have risen 30 percent from the fourth quarter of 1972 to the fourth quarter of 1973, accounting for a little more than one-fourth of the rise in the deflator during the same period. But this estimate is subject to some uncertainties. First, the weights may be inappropriate because the study on which they are based did not have as its object linking them to the GNP, and the methods used to update the study beyond 1969 are quite crude. Second, such a calculation assumes that these increases in crude commodity prices were passed through to final output dollar for dollar. Third, price increases on crude materials are passed through into final products with lags. These uncertainties would also pervade a similar calculation of the effect on the U.S. price level of price increases for domestically consumed raw commodities, both produced domestically and imported.

\section{The Model}

The ideal method for accomplishing this analysis would be to work prices of imported and domestically produced raw commodities through a suffi- 


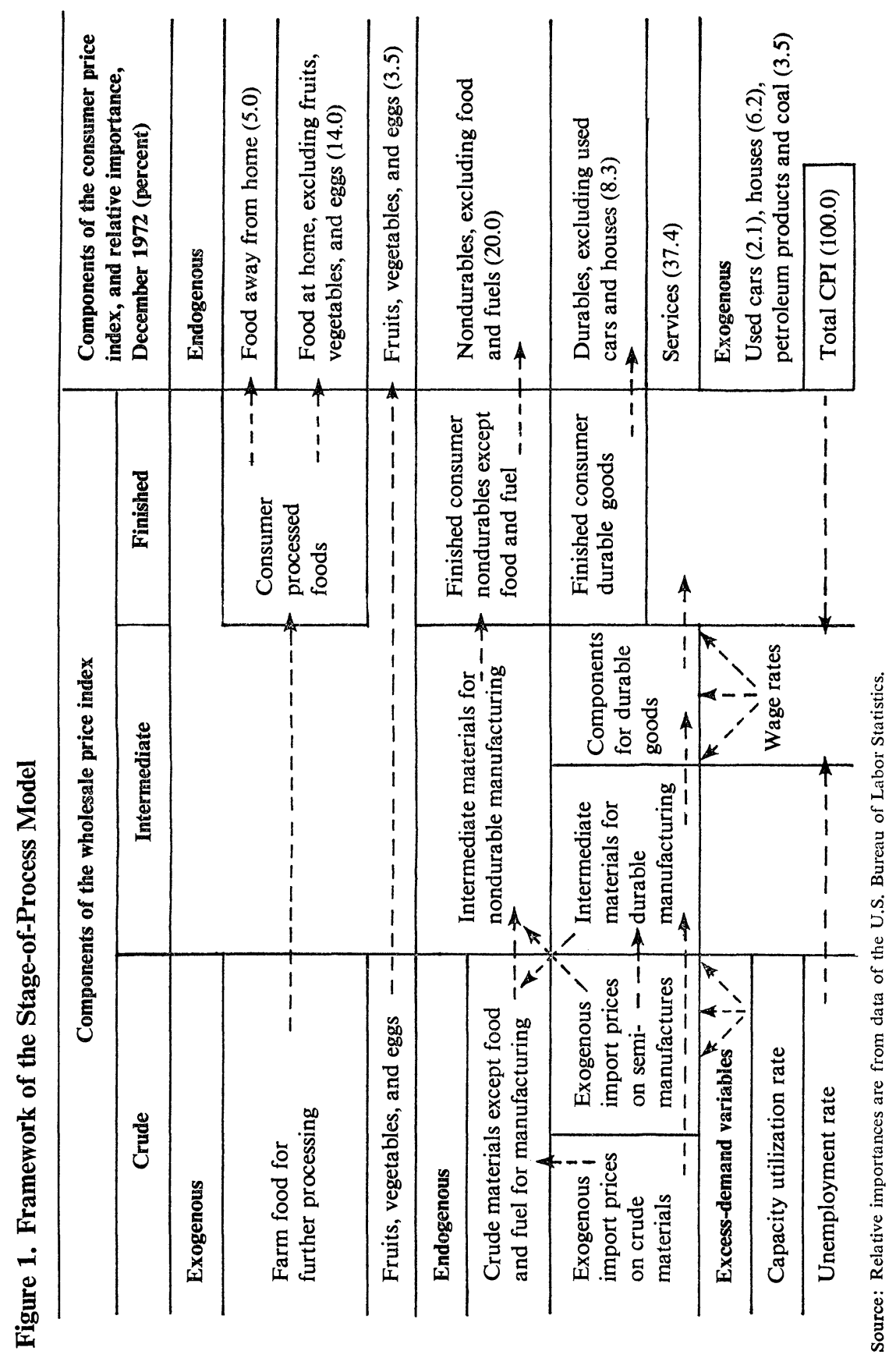


ciently disaggregated input-output (I-O) table that incorporated lags and variable margins. While no such framework is yet available, the stage-ofprocess framework used for this analysis approximates a dynamic I-O price model. ${ }^{2}$ The stage-of-process model is one in which raw commodity prices, together with other variables, are related to prices of intermediate materials and components which in turn are related to manufacturers' prices of both consumers' and producers' finished goods (see Figure 1). ${ }^{3}$ The prices of finished consumer goods are then used to explain the behavior of appropriate components of the consumer price index. At each stage of processing the model is disaggregated to reflect relationships for food, other nondurable goods, and durables. An equation has been estimated to explain price movements for the component in each endogenous block in the figure. In most cases the explanatory variables are prices at the earlier stage of processing, wage rates, and an excess-demand variable. While the estimated equations do not embody any precisely identified theory of price behavior, they come closest to approximating a variable markup model in which wage rates are proxies for standard unit labor costs.

Excess-demand variables (the unemployment rate and the rate of capacity utilization) and farm prices are the most important exogenous variables driving the system. But there are others. Prices of imported crude industrial materials (excluding fuels) explain part of the price movement of similar domestic commodities, reflecting the likelihood that imports are close substitutes for some of these commodities. For the same reason, prices of imported semimanufactured goods appear in price equations for intermediate goods. (Prices of imported finished goods were not significant in the equation for finished goods prices.)

Because very few time series data are conveniently arranged by stage of process, the matching of data for the model is difficult. ${ }^{4}$ But the structure of price behavior estimated from the data, such as they are, is reasonable. Thus the model implies an elasticity of the overall price of the CPI market basket (the endogenous part, accounting for 88.2 percent of the total) with

2. It approximates the particular I-O model in which the matrix of technical coefficients is amenable to triangularization.

3. My first version of such a model is described in U.S. Bureau of Labor Statistics, Office of Prices and Living Conditions, "Consumer and Wholesale Prices in a Model of Price Behavior by Stage of Processing," Research Paper 13 (1973), forthcoming in Review of Economics and Statistics. The equations for subsequent versions used in this analysis are available from the author on request.

4. A major effort is needed to establish a better data base for this kind of analysis. 
respect to wage rates of 0.685 ; that is, a 1 percent rise in wage rates adds 0.685 percent to the CPI. The CPI has an elasticity of 0.069 with respect to crude materials prices (excluding fuels and forest products). This is somewhat higher than the 0.057 share of these raw materials in domestic consumption during the decade of the 1960s (the period of most of the observations used to estimate the model). Most of the difference is attributable to agricultural products; they have a much higher weight in the CPI, because it is based on a 1960-61 market basket, than in the current-weighted consumption deflator of the national accounts.

\section{The Effect of Commodity Inflation in $\mathbf{1 9 7 3}$}

The first step in using the model for the analysis consisted of obtaining quarterly projections of the CPI and the industrial component of the wholesale price index for the period 1973:1 through 1973:4 and comparing the projections with the actual behavior of these indexes. Some variables, principally wages, farm prices, consumer prices of fossil fuels, and excessdemand measures, were taken as given.

\section{EFFECTS ON CONSUMER PRICES}

Actual and full-model projected values for the CPI are given in columns (1) and (2) of the upper bank of Table 2. A comparison between the two reveals that the model projections increasingly underestimate the change in the CPI throughout the four quarters of 1973.

As a next step, the model was run using actual values of domestic prices of crude industrial materials (which presumably include the effect of world crude prices, an explanatory variable in the equation for these materials). The CPI projections are not much different. This similarity reflects the fact that costs of crude materials-except for those of farm products and fuels, which are treated as exogenous in both simulations-are not a large element in prices of consumer commodities. Most of the underestimate of the CPI is attributable to the underprediction of the rise in prices for services and restaurant meals. Percentage margins for food in grocery stores also fell somewhat less than the model predicted as a result of the sharp rise in prices of farm products, but that rise was larger than any that occurred during the sample period. The increase in prices of consumer 
Table 2. Alternative Estimates of Impact of Raw Commodity Prices on U.S. Prices, by Quarter, 1973

Indexes, $1972: 4=100$

\begin{tabular}{|c|c|c|c|c|}
\hline \multirow[b]{2}{*}{$\begin{array}{c}\text { Year } \\
\text { and } \\
\text { quarter }\end{array}$} & \multirow[b]{2}{*}{$\begin{array}{c}\text { Actual }^{\mathrm{a}} \\
\text { (1) }\end{array}$} & \multicolumn{3}{|c|}{ Projection } \\
\hline & & $\begin{array}{c}\text { Full } \\
\text { model b } \\
(2)\end{array}$ & $\begin{array}{c}\text { Based on } \\
\text { actual } \\
\text { domestic } \\
\text { prices }^{\mathrm{c}} \\
\text { of crude } \\
\text { industrial } \\
\text { materials } \\
\text { (3) }\end{array}$ & $\begin{array}{c}\text { Based on } \\
\text { trend rates } \\
\text { for prices } \\
\text { of crude } \\
\text { industrial } \\
\text { materials } \\
\text { (4) }\end{array}$ \\
\hline & \multicolumn{4}{|c|}{ Consumer price index } \\
\hline $1973: 1$ & 101.5 & 101.4 & 101.4 & 100.7 \\
\hline 2 & 103.7 & 103.5 & 103.4 & 101.6 \\
\hline 3 & 105.8 & 105.3 & 105.3 & 102.5 \\
\hline \multirow[t]{2}{*}{4} & 108.2 & 107.0 & 107.1 & 103.4 \\
\hline & \multicolumn{4}{|c|}{ Subgroup of industrials component of wholesale price index ${ }^{\mathrm{e}}$} \\
\hline $1973: 1$ & 101.8 & 101.8 & 102.0 & 100.9 \\
\hline 2 & 105.0 & 103.2 & 104.3 & 101.6 \\
\hline 3 & 107.0 & 105.1 & 107.1 & 102.5 \\
\hline 4 & 109.6 & 107.5 & 110.4 & 103.5 \\
\hline
\end{tabular}

Source: Derived by author.

a. These data may differ somewhat from the official indexes of the U.S. Bureau of Labor Statistics because for the sake of consistency, the components-actual and projected-were assembled using relative importances in December 1972. Relative importances change almost continually but are published only once a year.

b. Assumes actual world crude prices, actual unit values of semifinished manufactures, and actual consumer prices for fossil fuels.

c. Assumes actual domestic crude prices, actual unit values of semifinished manufactures, and actual consumer prices for fossil fuels.

d. Assumes trend rates for domestic crude prices, for unit values of semifinished manufactures, and for consumer prices for fossil fuels.

e. Excludes about 30 percent of the WPI industries component, primarily fuels and construction materials.

nonfood commodities was overestimated by the model when prices of crude industrial materials were treated as exogenous.

Next a simulation was performed in which prices of all crude materials, farm and industrial, and consumer prices of petroleum products and coal were allowed to rise only at their trend rates. The trend rates per year during the sample period were 1.7 percent for farm prices of fruits, vegetables, and eggs; 0.6 percent for all other farm foods; and 1.7 percent for consumer prices of fossil fuels. The trend rate for crude industrial materials was determined as a function of capacity utilization in primary producing industries and of wage rates; it turned out to be 1.9 percent in 1973 . Trend rates for prices of semimanufactured imports were set equal to the prices 
Table 3. Effect of Commodity Inflation on the CPI and Its Major Components, Fourth Quarter 1972 to Fourth Quarter 1973

\begin{tabular}{|c|c|c|c|c|}
\hline \multirow[b]{2}{*}{$\begin{array}{c}\text { Component } \\
\text { of CPI }\end{array}$} & \multirow{2}{*}{$\begin{array}{c}\text { Relative } \\
\text { importance, } \\
\text { December } \\
1972 \\
\text { (percent) }\end{array}$} & \multirow[b]{2}{*}{$\begin{array}{c}\text { Actual } \\
\text { percentage } \\
\text { change }^{\mathrm{a}}\end{array}$} & \multicolumn{2}{|c|}{$\begin{array}{l}\text { Change attributable to } \\
\text { commodity inflation } \\
\text { (percentage points) }\end{array}$} \\
\hline & & & $\begin{array}{l}\text { Rise in } \\
\text { component }\end{array}$ & $\begin{array}{l}\text { Rise in } \\
\text { index for } \\
\text { all items }\end{array}$ \\
\hline All items & 100.0 & 8.2 & 3.7 & 3.7 \\
\hline Food & 22.5 & 19.4 & 13.0 & $\overline{2.9}$ \\
\hline Fossil fuels & 3.5 & 17.6 & 15.9 & 0.6 \\
\hline All other items ${ }^{b}$ & 74.0 & 4.4 & 0.3 & 0.2 \\
\hline
\end{tabular}

Source: Stage-of-process model described in text.

a. These values are derived by weighting components by their relative importance in December 1972 , and will therefore differ from changes based on official data of the U.S. Bureau of Labor Statistics. Official data show that the CPI rose 8.4 percent.

b. Includes gas and electricity.

in the equations for intermediate goods in which they are explanatory variables. The results are given in column (4) of Table 2.

The difference between columns (4) and (3) can be viewed as the effect that increases in raw commodity prices (in excess of the trend rates) had as they worked their way through the domestic production and distribution process and through prices of semifinished imports into the general price level, reinforced by higher consumer prices for fossil fuels. ${ }^{5}$ These effects account for 3.7 percentage points, or 45 percent, of the rise in the CPI of 8.2 percentage points during 1973 -that is, $(7.1-3.4) \div 8.2$. Table 3 shows the distribution of the impact of the raw commodity prices among the major components in the CPI.

During the 1973 simulation period the weighted average increase in the prices of crude materials entering the model was 43 percent, taking into account their importance in the model and the lags with which they affect the CPI. During 1973 these same prices without consideration of lags rose 40 percent. While in this case the difference happens to be small, lags could be far more significant over other periods. ${ }^{6}$

5. This analysis cannot include the effect of interactions between increases in raw commodity prices and variables not endogenously explained in the model, such as government policies which might well have been different in the absence of commodity inflation.

6. The difference between this 40 percent and the 30 percent mentioned earlier in connection with the GNP framework reflects, among other things, the difference between the price change associated with U.S. output of raw commodities and their importance in consumption. 
Since wages were treated exogenously in all the model simulations, the effect found for crude commodity prices does not include their impact on wage rates and subsequent feedbacks. The wage equations that are part of the full model (although not used in the simulations above) include the unemployment rate and a distributed lag of changes in the CPI. The coefficients of the CPI variable in the three wage equations average just under one-half. Thus the rise of 3.7 percentage points in the CPI during 1973 as a result of commodity inflation would have a substantial effect on wage rates in 1973 and 1974, according to these wage equations. But there is much to suggest that increases in the CPI have not had as much impact on wage settlements recently as has been attributed to them in the past by some studies. This is because an important part of the rise in the CPI in 1973 and so far in 1974 has been the result of higher prices for farm products and imported crude oil and petroleum products.

\section{EFFECTS ON WHOLESALE PRICES}

The lower bank of Table 2 contains a set of calculations, comparable to those reported for consumer prices, for a grouping of wholesale industrial prices. The grouping excludes about 30 percent of the industrials component, primarily fuels and construction materials. Fuels are excluded because refined petroleum prices are so poorly measured in the WPI that meaningful price relationships cannot be estimated; and construction materials are excluded because their prices affect mainly the construction component of the GNP deflator rather than the CPI. Columns (1) and (2) of the table reveal that the wholesale prices are increasingly underestimated during the course of 1973 when prices of crude industrial commodities are treated as endogenous. Column (3) makes clear that the predictions of the WPI improved noticeably when actual crude prices were used rather than the ones generated by the model. The rate of price increase is still underestimated in the first half of 1973, but by much less than it is when domestic crude prices were treated as endogenous. In the second half of the year, given actual crude prices, the rate of increase in the WPI is overestimated enough to yield a net overestimate for the year as a whole. Nonetheless, the absolute size of the prediction error is half that obtained when crude prices were endogenously determined. ${ }^{7}$

7. That the overestimate in the second half of 1973 was twice as large as the underestimate in the first half may reflect the effect of Phase IV actions in slowing the passthrough of increases in raw materials costs. 
A detailed examination of the results confirms the substantial underprediction of crude industrial prices in the model. For example, when crude prices are endogenously determined, the model predicts a rise of 20 percent for them for 1973, in comparison with the actual increase of 58 percent. And the predicted rise was as large as 20 percent only because of the large increase in world prices of crude materials that are exogenous to the model. Changes in capacity utilization in primary producing industries, although large, do not seem to explain as much of the price rise as might be expected. (I have not come across an aggregative equation for the prices of agricultural or nonagricultural raw materials that explains their behavior in 1973.)

Column (4) of the table reveals that, with crude prices allowed to rise only at their trend rates, the overall increase predicted for the WPI from the fourth quarter of 1972 to the fourth quarter of 1973 is only $3 \frac{1}{2} 2$ percent. Thus, the direct and indirect effects of the increases above trend in raw commodity prices, domestic and world, account for 72 percent-that is, $(10.4-3.5) \div 9.6$ - of the rise in the WPI industrials grouping over the four quarters (again ignoring any effect of higher prices of raw commodities on wages).

If the large increases in prices of lumber and wood products and fuels (the main industrial items excluded from this analysis) are also ascribed to the large increases in the prices of the raw commodities from which they are derived, then the share of the increase in industrial prices attributable to price increases for raw commodities becomes 84 percent.

If commodity inflation explains 72 percent of the rise in the WPI industrial grouping covered by the model, 2.7 percentage points of the 9.6 percent price rise for this grouping needs to be explained on other grounds. Labor costs have a weight of 0.42 in these price equations. ${ }^{8}$ Thus, if it is assumed that the 6.0 percent rise in unit labor costs in manufacturing during 1973 applies to this industrial grouping, wages would account for 2.5 percentage points. This calculation leaves only 0.2 percentage point as room for a rise in unit profits unless other unit costs (excluding labor and materials) fell. Of course, this excludes the rise in unit profits in industries that produce raw commodities, or intermediate materials whose prices rose partly in response to the increase in the prices of imports that are close substitutes.

8. That this share is lower than usual estimates is consistent with the fact that the WPI industrial grouping represents prices of gross shipments, not value added. Thus if there are three stages of process within this grouping, the labor share of the value of unduplicated sales is about two-thirds $\left(0.42+0.42^{2}+0.42^{3}\right)$. 
Earlier analysis of the predicted and actual values of the CPI suggested that unit profits of retailers on nonfood commodities produced in the manufacturing sector did not widen but narrowed. So did unit profits of grocery stores, though their decline was somewhat smaller than the model estimated, given the large rise in farm prices. On balance it appears that commodity inflation in 1973 was not accompanied by a generalized rise in unit profits, but rather that such rises in unit profits and profit-type income as did occur were concentrated in primary producing industries.

\section{Concluding Remarks}

The surge in raw materials prices was a worldwide phenomenon that deserves careful investigation to sort out the roles of various nations and of international trade and monetary relationships. Those issues lie outside the scope of this paper. But the analysis here does demonstrate that the effect of commodity inflation was substantial in 1973. Given the further rise in prices of crude commodities, particularly fuel, since the fall of 1973, and the potential inflationary impact of the lagged effect on wages of the price increases for crude commodities examined in this paper, commodity inflation seems likely to account for an important part of inflation in 1974. It already has in the first few months of the year. 